\title{
UNIVERSAL HEALTH COVERAGE PROGRAMME AND STUDENT INSURANCE BENEFITS IN GEORGIA
}

\author{
Nino Machavariani \\ Georgia, Tbilisi, Caucasus University, \\ School of Economics, Ph.D. Student
}

DOI: https://doi.org/ 10.31435/rsglobal_ws/31012019/6302

\begin{abstract}
ARTICLE INFO
Received: 10 November 2018

Accepted: 12 January 2019

Published: 31 January 2019

\section{KEYWORDS}

student health insurance, universal health coverage programme, voluntary health insurance, social services agency, private insurance, out-of-pocket payment.
\end{abstract}

\begin{abstract}
The aim of study was discovery and evaluation of existed options for students at contemporary insurance market, estimation of the awareness level among them and discovering correlation between level of ignorance and the rate of visiting healthcare facilities. Despite existence of instruction "Provision by insurer of all essential information to the customer while delivering insurance services" knowledge about student insurance details is extremely low, which is direct violation of consumer rights. No information comes from other governmental agencies, whose role in this regard apparently should be increased.
\end{abstract}

Citation: Nino Machavariani (2019) Universal Health Coverage Programme and Student Insurance Benefits in Georgia. World Science. 1(41), Vol.2. doi: 10.31435/rsglobal_ws/31012019/6302

Copyright: (C) 2019 Nino Machavariani. This is an open-access article distributed under the terms of the Creative Commons Attribution License (CC BY). The use, distribution or reproduction in other forums is permitted, provided the original author(s) or licensor are credited and that the original publication in this journal is cited, in accordance with accepted academic practice. No use, distribution or reproduction is permitted which does not comply with these terms.

Since its independence, Georgian health system has moved strongly away from the Semashko model, inherited from the soviet past. According to the report of European Observatory on Health Systems and Policies (a partnership hosted by WHO), published on 2017 - "The Georgian Healthcare system is now highly decentralized and was extensively privatized under reforms introduced from 2007 to 2012. These reforms were characterized by deregulation and trust in market mechanisms. During this period, most government spending on health was channeled through private health insurance companies, which were paid to provide a standard package of benefits for households living below the poverty line. In 2010, health insurance companies bid to be the sole provider of health insurance for families below the poverty line in a specific region. In exchange for this monopoly provision for a fixed term, the companies were required to invest in upgrading the hospital and primary care facilities in their region. This created a number of vertically integrated for-profit purchaser-providers at the regional level. Infrastructure and capital planning are driven by concerns for equitable geographical access to services, but planning in the health system is made much more complex by the dominance of private for-profit providers. Following extensive privatization and decentralization, most providers are independent of government in terms of ownership, governance and management. The pattern of vertical integration of pharmaceutical companies, private insurance companies and medical service providers is unusual in the European context and these companies are influential in the system. In 2013 was introduced the Universal Health Coverage Programme (UHCP), that extended the breadth of coverage to almost the whole population, most of whom had no health coverage before 2013. Since that time, private insurance companies and market mechanisms' roles were diminished and as the single payer in the health system for different government-funded covers under the UHCP came to the fore the Social Services Agency (SSA).

Generally, newly adopted system met demand for medical care among those who previously did not have health care coverage, and out of pocket payments considerably decreased. "Georgia still has some of the lowest utilization rates for outpatient care in Europe, but utilization of outpatient and inpatient care has more than doubled since the introduction of the UHCP (from 2.1 outpatient contacts 
per year in 2010 to 4 in 2015). Utilization of inpatient care is relatively high, but this is indicative of a strong preference in the system for care-seeking and treatment at more specialized levels of the system at the expense of primary care, as well as incentives in the system that encourage hospital care. Despite primary care being made free at the point of use for all, most of the UHCP budget is spent on inpatient services." 1

Since 2014, the UHCP has consistently overspent its budgeted amount. This was largely due to the rapidly growing demand for health services among those who were previously uninsured or lacked coverage for certain interventions. Alongside cover provided under the UHCP, the health budget also finances 23 vertical programmes for priority diseases and conditions. These vertical programmes seek to provide access to services for the whole population, but with varying depth of coverage. The vertical programmes include: mental health, diabetes management, child leukemia services, dialysis and kidney transplantation, palliative care, and a range of public health protection programmes including tuberculosis control, vaccination programmes and the innovative hepatitis $\mathrm{C}$ programme, which aims to achieve a $90 \%$ reduction in prevalence by 2020 . Georgia has a high prevalence of hepatitis $\mathrm{C}$ infection, mainly due to inadequate infection control in health care settings and unsafe injections among persons who inject drugs. In 2015, 7.7\% of the adult population was living with hepatitis C. By 2017, 30\% of the estimated population infected by hepatitis C in Georgia had received treatment, with cure rates of $82 \%$ and $98 \%$ depending on the regimen.

In May 2017, the most affluent households (about 43000 people, whose annual income is above 40000 Georgian lari (GEL)) were excluded from the UHCP on the understanding that they would purchase Voluntary Health Insurance. Health expenditure by service input is dominated by expenditure on pharmaceuticals, which was 38\% of Total Health Expenditure by 2015 (Ministry of Labor, Health and Social Affairs, 2018).

The UHCP dominates public expenditure on health, accounting for $75 \%$ of public spending on health in 2016. Of total public spending on health, $67 \%$ was on hospital services, while $25 \%$ went to primary care providers (World Bank, 2017). With the introduction of the UHCP, there was a fall of $49 \%$ in spending on medical goods (mainly pharmaceuticals), which is partly related to generous inpatient care coverage which includes necessary medicines, while benefits for outpatient pharmaceuticals are limited. There was also a $79 \%$ fall in administration costs, which were calculated differently to exclude profits from the administration costs of private insurance companies as the system moved to one with a single payer (World Bank, 2017).

In essence, there are three patient pathways in Georgia: the route for those covered under the UHCP and some vertical programmes; the route covered by Voluntary Health Insurance; and the private 'out-of-pocket' route. The route taken also depends on the condition (i.e. whether or not the condition is covered under the particular insurance package or under the UHCP - or other programme). Patients can access inpatient treatment covered under the UHCP while bypassing primary care. For inpatient services under VHI, a referral from a registered primary care provider is needed. The bypassing of primary care entirely is common and there is a strong patient preference for accessing care at more specialized levels (Smith, 2013).

Access to essential medicines is also cheaper in emergency and inpatient care settings.

Under the UHCP, in order to get a planned hospital service, the patient chooses the provider and they or the medical facility are required to submit the necessary documentation to the SSA for authorization. Once authorized, the patient is issued with a voucher that also indicates what proportion of the costs will be covered by the government and how much the patient is expected to pay (generally between 10\% and 30\%). Previously, patients under Voluntary Health Insurance had more choice of provider, but now many providers are integrated with private insurance companies and these tend to have preferred providers, thus limiting patient choice. Some primary care doctors are also employed or subcontracted by inpatient care providers and they do proforma referrals to their allied hospitals." ${ }^{2}$

As with the UHCP, many VHI packages and vertical programmes are not totally comprehensive, and many interventions are still not covered. Patients are free to self-refer to any service provider but the patients then bear the full cost of care themselves. The scope for self-referral makes it difficult for primary care physicians to coordinate care.

\footnotetext{
${ }^{1}$ E. Richardson, N. Berdzuli “Georgia: Health system review”. Health Systems in Transition, 2017; 19(4):1-90. (http://www.healthobservatory.eu), (accessed 26/10/2018)

${ }^{2}$ E. Richardson, N. Berdzuli “Georgia: Health system review”. Health Systems in Transition, 2017; 19(4):1-90. (http://www.healthobservatory.eu), (accessed 26/10/2018)
} 
Out-of-pocket (OOP) spending in health in Georgia is high when compared with OOP spending across the European region, but it fell following the introduction of the UHCP, even though government expenditure on health increased 126\% from 2012 to 2016. Since the introduction of the UHCP, catastrophic OOP spending on inpatient care has halved, but average OOP spending on outpatient pharmaceuticals has almost doubled. This is not due to any change in coverage but because pharmaceuticals in Georgia are relatively expensive, generics are not always available (and often are of a less demand), and the reliance on imports makes pharmaceutical prices vulnerable to economic shocks such as the depreciation of the lari. Despite all pros coming from UCHI, it became heavy burden for the Georgian economy. For more visibility, in 2015 instead of 470 mil GEL allocated for UHCI from the state budget were spent 573 mil GEL, in 2016 were spent 645 mil GEL versus 570 mil GEL allocated in the budget. 2017 budget was planned accordingly- 660 mil GEL. Correspondingly, money spent by private insurance sector also increased, please see chart below:

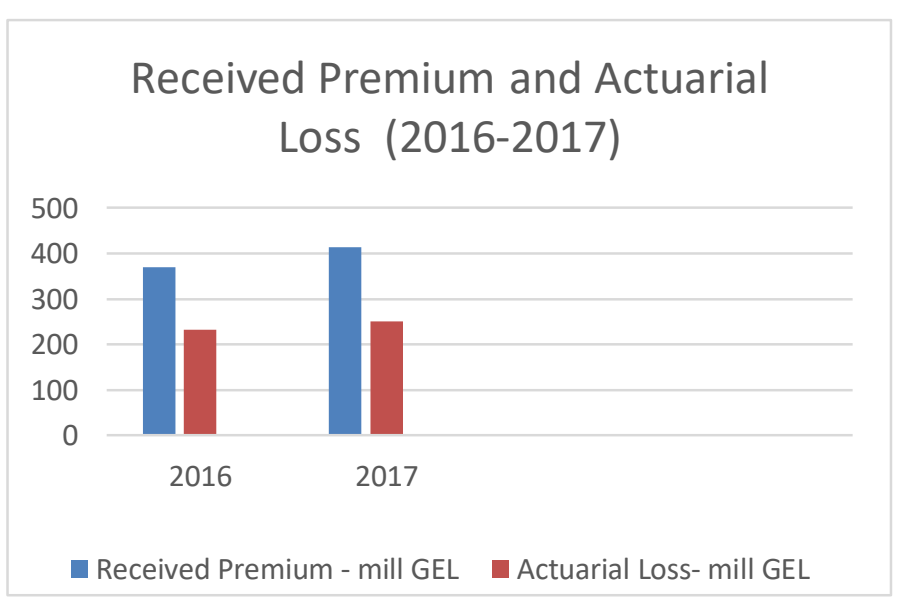

Chart. 1. Developed Insurance Premium and Actuarial Loss in 2016-2017, GeoStat.ge (12)

\section{Student Insurance Development}

Taking into consideration all mentioned above challenges, students appear to be one of the vulnerable segments of Georgian social categories. Student Insurance was introduced in Georgia in September 1, 2012. Provision of it was supported by private insurance companies in rural areas, as well as by "Archimedes Global Georgia" in the capital. After declared bankruptcy of "Archimedes" in 31/12/ 2013, all students, studded in Tbilisi, from 01/01/2014 were transited to the Universal Programme, and from 01/09/2014 all students fell under UHCP, regulated and administered by Social Services Agency.

Eligible for that type of universal healthcare programme is a student, citizen of Georgia, studded:

A. in authorized higher educational establishments on Bachelor's, Master's, Medical or Dentist's as well as Georgian language educational programmes; programs.

B. in vocational training schools on $4^{\text {th }}$ and $5^{\text {th }}$ stage as well as higher vocational education

Duration of insurance period depends on the duration of educational programme and not on the age of a student. Thus, in case of Bachelor's degree programme continues for 48 month, Master's degree programme for 24 month, Georgian language study programme -for 12 month, etc. Termination of student insurance can be caused by completion of insurance period, death of insured, rejection of insurance by its holder, committing to prison or another restraint facility, termination or stay of student status with exceptions for pregnancy, delivery, child care and health condition. Continuation of such exceptional period should not exceed 1 calendar year.

In the frame of student insurance, beneficiary can receive following services (cost-free, without additional payments): ultrasound of all systems, all systems roentgenography / roentgenoscopy, consultation of all specialists, consultation of family doctor in the clinic and at beneficiary's home, blood general analysis, urine general analysis, lipid spectrum, creatinine, glucose, electrocardiography, hidden blood analysis, $100 \%$ cost of emergency care and $80 \%$ cost of planned surgical interference. While proposed universal services have satisfied needs of insured and made available timely medical care for students, fell under mentioned above categories, despite material wealth of their families, activation of such insurance in case of necessity is simple, doesn't take time and does not exclude simultaneous utilization of private insurance package, this insurance has its discrepancies. Namely, it does not cover dentist care, medications costs, and is not popularized at all. Many claims difficulties in obtaining particular information about student insurance. 
From 23 of June 2018, Eastern Europe University has signed cooperation memorandum with Acad. N. Kipshidze Central University Clinic (Republic hospital) for provision medical care services to EEU students in the frame of Universal Healthcare Insurance Programme. The value of one students' package is, as it is foreseen in UHIP, 15000 GEL. Besides covering mandatory medical services, Republic Hospital proposes for EEU students 30-50\% discount for advanced technological researches (computer tomography, magnetic resonance, etc). From September 2019 is planned to provide same services to student's family members.

Starting from September 2018, some private insurance companies proposed insurance packages for students, as well. For instance, IGG has developed special package for Caucasus University students, with monthly premium- 20 lari. It gives an opportunity to utilize such services as consultation of family doctor in clinic and at home, dental services, copayment for prescribed medications, conduction of high technological research procedures (computer tomography, MRT, etc.). Besides, students are proposed individual limit of $4000 \mathrm{GEL}$ for planned hospitalization. If, for instance universal student insurance allocates for that propose only $70-80 \%$ of sum, private insurer fills amount up to $20-30 \%$ as a copayment in accordance with the limit. In case of outpatient and inpatient emergency company covers 6000 GEL limit.

Another privately owned insurance company «GPI Holding», proposes students following reductions:

- $20 \%$ reduction for travel insurance while travelling abroad

- $10 \%$ for family package "Medi Policy" covering beneficiary's family members.

- $10 \%$ for package "Auto Policy" for the student and his/her family members.

- One moth home insurance "Policy Comfort"

- $20 \%$ for dentist care in GPI Holding's provider clinic "Universe"

- $10 \%$ for medical services in GPI Holding provider clinic "Curacio".

New product was delivered to the Georgian insurance market by another insurance company "Global Benefits Georgia". Company has developed special policy package for Georgian and international students, that is tailored to individual requirements of each student. This package can be even used while travelling and studding abroad, as beneficiary gains an access to about 10000 of high standards medical facilities- Global Benefits Group's worldwide providers, avoiding additional costs and bills payment procedures. Among benefits of that package is GBG Assists' 24/7 hotline, were qualified professionals are consulting customers and helping them in planning medical services. "Student Protector Policy" holder can choose desirable geographical as well as medical coverage.

The most recent proposal, focused on the improvement of beneficiary service in the frame of student universal insurance was introduced on 25 October 2018, by "Evex" corporation. It covers $100 \%$ of all services, foreseen by universal student insurance, but in addition provides $30 \%$ discount for services do not covered by state insurance, as well as 30\% discount for all types of dental services. As an additional benefit, registered in Evex corporation student can receive service in any of 15 "Evex" polyclinics all over the country, become candidate for monthly stipend (100 GEL during 6 month), participate in employment program, undergo simplified registration in special "Evex" registration centers (settled up in educational institutions and in 8 Evex polyclinics, located in 8 districts of Tbilisi). "Evex" corporation also declared participation in different student activities like lectures and master classes, sport activities, etc. due to propaganda of healthy nourishment, healthy lifestyle and heath monitoring (preventive care).

On the basis of international standards, Georgian Insurance State Oversight Service has developed instruction on "Provision by insurer of all essential information to the customer while delivering insurance services" and had introduced it on 24 March, 2017. Instruction reflects obligation of insurer, on each and every stage of provision of insurance services, including product proposing, as well as after signing a contract to adequately inform customer about all essential information including standard procedure of claims revision. The regulation of such type, supposed to increase service quality and prevent potential lawsuits.

International Experience. Currently accumulative packages are not obligatory in Georgia. In contrary, in European countries such as Germany, Holland, Belgium and Sweden student insurance is mandatory. In Spain, for instance, all students before age of 28, undergo accumulative insurance automatically, they are not paying for it, as it is included in tuition fees. In Germany, the least student insurance premium is $46 €$. Besides beneficiary's life insurance it incorporates different medical costs, including visits to dentist. French students to receive an accumulative package are contracting special agencies. Annually it costs about $250 €$ and represents part of universal accumulative social insurance. 
In United States only $10 \%$ of population enjoys state covered insurance, other $90 \%$ uses private insurance companies' services. American students spend on insurance 100-500 \$ annually. In Japan there is in place state system of mandatory accumulative insurance, that covers not only life/death insurance, but visits to different specialists, operations, treatment and nourishment in hospitals, and all necessary medications. Accumulative life and health insurance gives an opportunity not only to put aside monetary resources, but in case of necessity ensures adequate level of medical service. International insurance packages nowadays become of a big interest for exchange program students, travelling from Georgia to different countries, while exact knowledge of foreign requirements helps to save and properly allocate money, purchasing adequate

Research. Taking into consideration that student insurance problem is as important as actual, we suggested a hypothesis, that universal, Georgian government funded student insurance is underused by its beneficiaries, because of informational vacuum in this regard. To another handcoming to Georgia international students represent potential market for Georgian private insurance sector that is not properly researched and, thus, utilized.

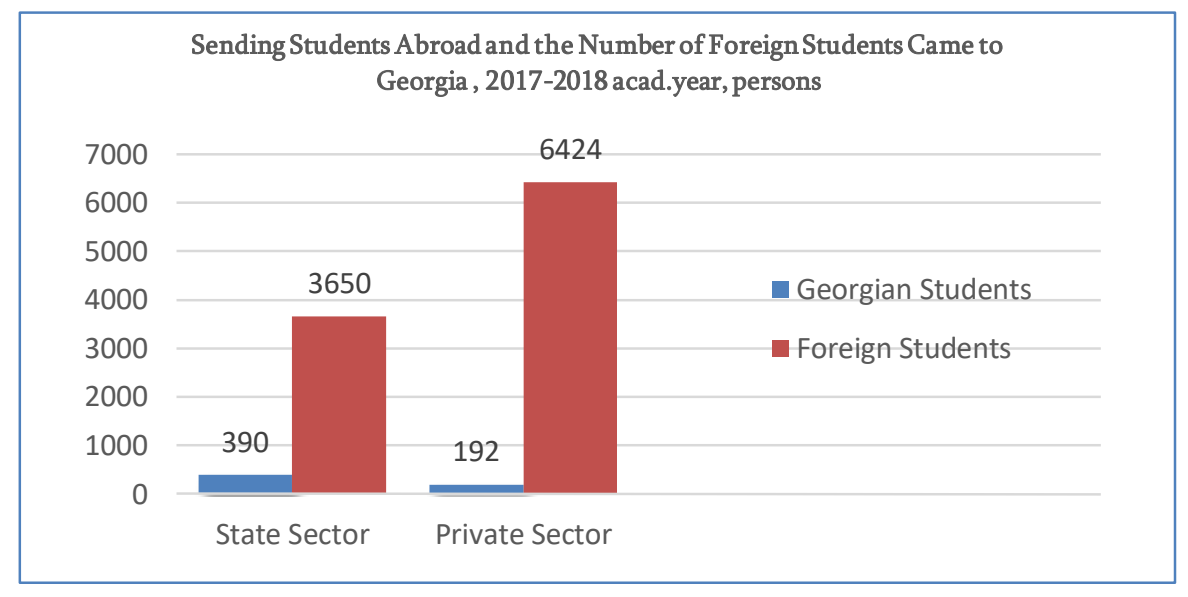

Chart. 2. Georgian students sent abroad (blue) and international students came to Georgia (red) in 2017-2018 a.y.

So, the aim of study was estimation of the awareness level among students and discovering correlation between level of ignorance and the rate of visiting healthcare facilities. If in the first part of study, where we revealed existing preconditions in Georgian student insurance market were used mainly qualitative research methods as well as interviews with educational, medical, state oversight, insurance facilities representatives and students. To investigate the problem and prove the hypothesis, randomized quantitative study was conducted. Study subjects were: Georgian as well as international students of Free University of Tbilisi, The University of Georgia, Business and Technology University, Caucasus University, Sulkhan-Saba Orbeliani Teaching University, Business Academy of Georgia and vocational training schools. Study object- level of awareness among Georgian students about student insurance and employment by international students Georgian private insurance. Total number of respondents was 565 (517 Georgian and 48 International students). On Bachelor's educational programs study 93\% respondents, on Master's- $5 \%$, in vocational facilities- $\left(5^{\text {th }}\right.$ degree $)-1 \%$, other $-1 \%$.

In regard of Georgian students' awareness about possibility to get free of charge medical services, positive answer was given by $41 \%$, while negative by $59 \%$.

Only $13 \%$ of Georgian students utilizes medical services of ultimate student insurance and only $15 \%$ is aware what services are for their disposal without any fee. $25 \%$ thinks that information about student insurance is not approachable for them, $26 \%$ easily gets it, while $49 \%$ find difficult to answer this question. $16 \%$ counts that their consumer rights at insurance market are protected, while $8 \%$ answers negative, $76 \%$ abstains from the answer.

As it was revealed by our study, $29 \%$ of international students do not have any insurance, $28 \%$ have private insurance packages from their home countries, $14 \%$ have Georgian private insurance, and $29 \%$ do not know "what is it"! $29 \%$ (all students without insurance) are going to purchase it in nearest future. Only $10 \%$ from Georgian and $25 \%$ from international students confirmed an insurance proposal from their universities and $64 \%$ and $57 \%$, correspondingly, never heard about such. $26 \%$ and $18 \%$ from each group did not understand what they were asked about. 
Healthcare facilities are often visited by $7 \%$ of Georgian Students, 53\%- visits them very seldom, $8 \%$-do not refer to healthcare facilities at all, 32\% refer to facilities 1 to 3 times in a year.

\section{Conclusions. Recommendations.}

There is noticeable correlation between numbers of informed about state insurance students and students visited medical care facilities. Despite existence of instruction "Provision by insurer of all essential information to the customer while delivering insurance services" knowledge about student insurance details is extremely low, which is direct violation of consumer rights. No information comes from other governmental agencies including Ministry of Education, whose role apparently should be increased.

Georgian Student Insurance is not mandatory, it can be applied for, in case of necessity. As for preventive examinations, only limited tests are foreseen in this package and only after family doctors' prescription. As it was mentioned above, limit of the package is 15000 lari for hospital services and about 12000 for oncological patients. Majority of students is not informed about this allocations and application for these services is low. It is important to improve supporting of primary health care. In addition, education about healthy lifestyle should be promoted among adolescents.

Remains open issue of preexisted conditions of potential beneficiary. Currently it is not taken into consideration neither by government funded universal insurance, nor by private insurance companies.

Only accredited educational facilities can insure their students, otherwise they can be treated as citizens. Major concern- quality of provided services, overload of facility, lake of preventive observation.

Positive features of students insurance - person picks desirable facility, about $20 \%$ co- finance for extra services.

As students represent low risks group, they can be offered better packages for lower premiums.

Seems reasonable to continue research in terms of identification international students' requirements and needs in insurance products, to facilitate coverage of this comparatively new segment.

Some NGOs are closely studying activities around student insurance, which seems to be positive sign of social interest and activity.

\section{REFERENCES}

1. Bondi, S. (09/2009). Austrian Health Care. Retrieved from Association of Americans Resident Overseas: https://aaro.org/aaro-around-the-world/246-austrian-health-car(accessed 10/26/2018, 10:51)

2. Coleman J., Hagell A. (2015) "Young people, health and youth policy". Y \& P , 114, 17-30, https://www.researchgate.net/publication/280599972_Young_people_health_and_youth_poli-cy, (accessed $10 / 26 / 2018,12: 20)$

3. Decree of the Government of Georgia 553, 14/04/2014 (accessed 10/26/2018, 12:35)

4. Decree of the Government of Georgia N133 (04/15/2018)

5. Decree of the Government of Georgia N218 (09/12/2009).

6. Decree of the Government of Georgia N165 (07/05/2012).

7. Kim J. Y. (2014) THE GLOBAL PUSH FOR UNIVERSAL HEALTH COVERAGE, World Bank Group https://www.moh.gov.ge/uploads/files/oldMoh/G-J/1.pdf - (accessed 10/26/2018, 12:05)

8. Lacabidze I., Skhirtladze S., Farjiani L., Verulava T. (2017) Healthy Behavior in Students. Scientific Reviewed Journal "Health Policy, Economics and Sociology", 3, 119-129

9. Magaldadze M., Kodelashvili T., Sulashvili S., Grdzelishvili A. (2018) Students healthcare insurance and their appealability to family doctor. Proceedings of IV Scientific Conference - Actual Issues of Health Policy, Economics and Sociology, 1, 52-54

10. Richardson E., Berdzuli N. "Georgia: Health system review". Health Systems in Transition, 2017; 19(4):190. (http://www.healthobservatory.eu), (accessed 10/26/2018, 10:57)

11. Smith O. Georgia's Medical Insurance Program for the Poor. UNICO Studies Series. (2013) Washington DC, World Bank (http://documents.worldbank.org/curated/en/578731468249 286738/Georgiasmedical-insurance-program-for-the-poor, accessed 10/26/ 2018, 16:00)

12. Student Insurance. (2018). The Dutch healthcare system. Retrieved from Student Insurance: https://www.studenten-zorgverzekeringen.nl/en/dutch-healthcare-system.html - (accessed 10/26/2018, 11:45)

13. Universal health care - the main priority of Global health care - https://www.moh.gov.ge/ka/531/ (accessed 10/26/2018, 11:30)

14. https://www.internationalstudentinsurance.com/france-student-insurance/ - (accessed 10/26/2018, 12:15)

15. https://www.studying-in-germany.org/health-insurance-germany-guide/\#foreign-students (accessed $10 / 26 / 2018,12: 25)$

16. http://www.geostat.ge/?action=page\&p_id=205\&lang=geo (accessed 10/26/2018, 12:45)

17. http://www.geostat.ge/?action=page\&p_id=2608\&lang=geo (accessed 10/26/2018, 15:00)

18. http://eeu.edu.ge/portfolio/7117/ (accessed 10/26/2018, 12:45)

19. http://bit.ly/EvexforStudents (accessed 10/26/2018, 15:30) 